\title{
Anencephaly and spina bifida (ASB) and retroversion
}

\author{
MICHAEL R. BUCKLEY \\ From the Department of Obstetrics and Gynaecology, Ege University, Izmir
}

SUMmaRY Despite the wealth of epidemiological material of the last decade, birth defects are still the chief cause of perinatal mortality and no significant breakthrough in understanding or reduction has yet been seen. Many proposed aetiological factors are still being evaluated. This report suggests a possible, simple, remediable factor in the aetiology of defects of the central nervous system.

The chance remark of a patient some years ago prompted a retrospective case-sheet study of the mothers of anencephalics in a Merseyside hospital. Of 47 case sheets examined, only 23 gave specific information of uterine position in the non-pregnant state. Of these, $14(61 \%)$ were retroverted and nine (39\%) were anteverted. One case of anecdotal interest recorded the uterus as anteverted on two occasions and during this time the patient had had two normal babies. There were then five records of the uterus being retroverted, in the midst of which the patient had an anencephalic baby.

It was recognised that a small retrospective case-sheet study was of limited value because of the inadequacy and lack of guarantee of reliability of the records. For this reason the following study was undertaken as part of a more comprehensive survey of defects of the central nervous system.

\section{Material, methods, and results}

During a three-year survey, 113 cases of ASB births occurred in the hospitals of Izmir, a large city in western Turkey. Of the 77 cases who lived near enough to be recalled, 37 returned for discussion and examination. Most of the rest were lost because of change of address. Patients returning were questioned to complete information for the general survey, and examined and counselled with regard to further pregnancies. When possible, an independent vaginal examination was made by a colleague to assess uterine position. Of the 37 patients, 12 were already pregnant on recall. Of the remainder, 12 had an anteverted or mid-position uterus, 11 had a retroverted uterus, and two had acutely flexed and leave-rotated uteri. Including these two in the malposition group, there were $48 \%$ normal and $52 \%$ abnormally positioned uteri.
A control group was made of 100 patients attending the routine gynaecological outpatient clinic. It is recognised that such a group may tend to give a slightly higher rate of retroversion than that in the normal population. Post-menopausal and pregnant patients and women with palpable tumours were excluded. Otherwise the group represented a typical gynaecological clinic cross-section. The obtained retroversion rate of $18 \%$ approximates to the generally accepted normal incidence of about $15 \%$ (Jeffcoate, 1967).

\section{Discussion}

Non-fixed retroversion is properly regarded in most gynaecological circles as a normal variant. However, the above study raises the question of whether there might be some theoretical consideration which would give support to the apparent relation between retroversion and ASB. The early work of Siockard (1921) with fish and later mammalian work (Murakami and Katsunuma, 1955; Degenhardt, 1956; Ingalls and Curley, 1957; Ovchinnikova, 1974) demonstrated that a wide range of abnormalities of the central nervous system could be induced by anoxia of the mother. The localisation and extent of the anomaly depended on the timing, duration, and severity of the anoxia.

Attention has been turned to the micro-environment and to the histotrophic phase of nutrition. The criticalness of location and adequacy of nidation and early placentation is demonstrated in several reports (Suter, 1948; Record, 1956; Turnbull, 1956). These show that a third of all viable babies from extrauterine pregnancies had major or minor abnormalities, that there is a doubled rate of abnormalities, especially anencephaly, associated with placenta praevia, and a doubled rate of fetal 
abnormalities in pregnancies showing threatened abortion. It seems clear that disturbances of nutrition or oxygenation in the early weeks of human pregnancy significantly increase the risk of fetal abnormality.

In recent years the vasculature of the human uterus has been well studied, moving from the static picture of injection techniques (Lundgren, 1957) to more recent rheometric methods using radioactive isotopes (Rekonen et al., 1976). Böving (1962) demonstrated that the apposition of an endometrial end-artery to the trophoblast knob is critical in the formation of placental cotyledons. Reynolds (1967), noting the reverse side of the coin, pointed out that topographic, normal and abnormal relations of the blood supply of the non-gravid uterus therefore govern the ultimate potential for support of the gestation mechanism by adequate placentation. Studies of oxygen partial pressure in the uterine cavity have been conducted by Yedwabet al. (1976). They found that unlike the cervical canal the uterine cavity $\mathrm{pO}_{2}$ remained constant throughout the menstrual cycle, reflecting presumably the endometrial $\mathrm{pO}_{2}$. However, despite considerable experimental work in animals, and much study on blood flow and oxygen tension in the developing pregnant uterus, there is still very little information on the vital phase of implantation and early placentation which may so crucially influence the development of the fetus. There is also apparently no reference in the literature to the retroverted uterus in this context.

In retroversion there is distortion of the normal anatomy, demonstrated by the observation at operation that the pampiniform plexus of a retroverted uterus is frequently engorged. Venous congestion means back pressure on the endometrial vessels and therefore a presumed fall in the oxygen tension in the endometrium. If there is any deficiency in oxygenation due to the site of the implantation or poor placentation, it seems that a retroverted uterus with reduced capillary $\mathrm{pO}_{2}$ will exaggerate this, resulting in increased risk of fetal abnormality.

This study identifies a significantly high incidence of retroversion in mothers of ASB infants. A causal relationship, although suspected, is not proven. However, a theoretical basis for such a relationship is suggested. The validity of the findings need first to be proved in a larger sample. Then the proposed underlying basis could be checked by testing the $\mathrm{pO}_{2}$ of venous blood in anteverted and retroverted non-pregnant uteri. The study suggests an area of further investigation which could lead to the identification of a significant factor in the aetiology of defects of the central nervous system and possibly of other birth defects, which in certain cases is remediable.

Reprints from Dr. Michael R. Buckley, Krankenhaus Elim, Hohe Weide 17, 2000 Hamburg 19, West Germany.

\section{References}

Böving, B. G. (1962). Essentials for penetration of the trophoblast. Contributions to Embryology, 37, 33-35.

Degenhardt, K. H. (1956). Phasenspezifität $\mathrm{O}_{2}$ Mangel induzierter Wirbelsäulenmißbildungen bei Kaninchen. Acta Genetica et Statistica Medica, 6, 246-252.

Ingalls, T. H., and Curley, F. J. (1957). Principles governing the genesis of congenital malformations induced in mice by hypoxia. New England Journal of Medicine, 257, 1121-1127.

Jeffcoate, T. N. A. (1967). Principles of Gynaecology, third edition, p. 41. Butterworths: London.

Lundgren, N. (1957). Studies on the vascularity of the corpus of the human uterus. Acta Obstetrica eP Gynaecologica Scandinavica, Supplement No. 4, 38ल 1-115.

Murakami, U., and Katsunuma, S. (1955). Sur la périodę critique où apparait la pseudencéplalie des embryons et la manifestation active de germe héréditaire. Comptes Rendus des Séances de la Société de Biologie et de seS Filiales, 149, 2281-2282.

Ovchinnikova, G. A. (1974). Effect of experimental uterine ischaemia during the development of the utero-placentat circulation on embryonic growth. Patologicheskaia Fiziologiia i Eksperimental'naia Terapiia, 6, 54-57.

Record, R. G. (1956). Observations related to aetiology of placenta praevia with special reference to influence of age and parity. British Journal of Preventive and Social Medicine, 10, 19-24.

Rekonen, A., Luotala, H., and Pitkänen, M. (1976). Measurement of intervillous and myometrial blood flow by an intravenous $133 \mathrm{Xe}$ method. British Journal of Obstetrics and Gynaecology, 83, 723-728.

Reynolds, S. R. M. (1967). Cellular Biology of the Uterus, p. 7. Edited by R. M. Wynn. North Holland: Amsterdam

Stockard, C. R. (1921). Developmental rate and structural expression. American Journal of Anatomy, 28, 115-266.

Suter, M., and Wichser, C. (1948). Fate of living viable babies in extrauterine pregnancies. American Journal of Obstetrics and Gynecology, 55, 489-495.

Turnbull, E. P. N., and Walker, J. (1956). Outcome of pregnancy complicated by threatened abortion. Journal of Obstetrics and Gynaecology of the British Empire, 63, 553-559.

Yedwab, G. A., Paz, G., and Hommonai, T. Z. (1976). The temperature, $\mathrm{pH}$ and partial pressure of oxygen in the cervix and uterus of women and the uterus of rats during the cycle. Fertility and Sterility, 27, 304-309. 